\title{
Ultrasound-guided greater occipital nerve block with botulinum toxin for patients with chronic headache in the occipital area: a randomized controlled trial
}

\author{
Jae Hyung Ryu, Jae Hang Shim, Jong Hoon Yeom, Woo Jong Shin, \\ Sang Yun Cho, and Woo Jae Jeon \\ Department of Anesthesiology and Pain Medicine, Guri Hospital, Hanyang University College of Medicine, Guri, Korea
}

\begin{abstract}
Background: Ultrasound-guided greater occipital nerve (GON) block has been frequently used to treat various types of headaches, and botulinum toxin has recently begun to be used in patients with headache. Our study presents the longterm effect of botulinum toxin on GON block using ultrasound in patients with chronic headache in occipital area.

Methods: Patients with occipital headache were divided into two groups (bupivacaine: BUP group [ $\mathrm{n}=27$ ], botulinum toxin: BTX group [ $\mathrm{n}=27]$ ), and ultrasound-guided GON block was performed at the C2 level. GON was detected with ultrasound and distance from GON to midline, from the skin surface to GON, and size of GON were measured in both groups. Visual analogue scale (VAS) scores and Likert scale were assessed at pretreatment and at 1, 4, 8, and 24 weeks after treatment in both groups.

Results: The distance from GON to midline was $18.9 \pm 4.4 \mathrm{~mm}$ (right) and $17.3 \pm 3.8 \mathrm{~mm}$ (left). The depth from the skin was $12.9 \pm 1.5 \mathrm{~mm}$ (right) and $13.4 \pm 1.6 \mathrm{~mm}$ (left). GON size was $3.1 \mathrm{~mm}$ on both sides. The VAS score and patient satisfaction score (Likert scale) in 4, 8, and 24 weeks after injection were superior for the BTX than the BUP group.

Conclusions: Ultrasound-guided GON block using BTX is effective in reducing short-term and long-term pain in patients with chronic headache in the occipital area.
\end{abstract}

Keywords: Botox; Greater occipital nerve block; Headache; Likert scale; Long term follow up; Ultrasound; Visual analogue scale.

Corresponding author: Jae Hang Shim, M.D., Ph.D.

Department of Anesthesiology and Pain Medicine, Guri Hospital, Hanyang University College of Medicine, 153 Gyeongchun-ro, Guri 11923, Korea

Tel: +82-31-560-2400, Fax: +82-31-563-1731

Email: jhshim@hanyang.ac.kr

ORCID: https://orcid.org/0000-0002-3533-6407

Received: April 8, 2019.

Revised: May 21, 2019 (1st); June 2, 2019 (2nd).

Accepted: June 3, 2019.

Korean J Anesthesiol 2019 October 72(5): 479-485

https://doi.org/10.4097/kja.19145

\section{Introduction}

Headache is a common pain that is induced by a variety of causes. Primary headaches can be categorized as tension-type headaches, migraine, trigeminal autonomic cephalalgia, and other primary headache disorders according to the 3rd International Classification of Headache Disorders [1]. The greater occipital nerve (GON), which is mostly derived from the C2 dorsal root, is the main sensory nerve of the occipital area [2]. GON block is a common method used for the treatment of these various headaches, especially occipital headache, and a number of publications have indicated its practical usefulness [3-5].

(c) This is an open-access article distributed under the terms of the Creative Commons Attribution Non-Commercial License (http://creativecommons.org/ licenses/by-nc/4.0/), which permits unrestricted non-commercial use, distribution, and reproduction in any medium, provided the original work is properly cited. 
However, conventional methods using only anatomical landmarks for finding GON are difficult to demonstrate accurate nerve blockage and thus may raise questions about therapeutic efficacy. We have confirmed through preliminary tests that ultrasound guided block at the origin of GON is more accurate and effective than conventional methods. In addition, local anesthetic agents or steroids can be used for treatment of headache, and various opinions on the possibility of botulinum toxin use to prolong the treatment effect have been recently reported [6].

We compared the treatment effect of botulinum toxin with that of local anesthetics by using real-time ultrasound guided block, which is a more accurate method for headache patients. The effect of botulinum toxin on GON block during chronic headache in the occipital area with various causes and anatomical parameters for more accurate procedure was investigated.

Therefore, the primary aim of this study was to assess the effectiveness of GON block using ultrasound and evaluate the satisfaction of patients in the treatment of chronic headache in the occipital area for up to six months. Secondary aims included obtaining anatomic parameters to enhance safety and confirming the occurrence of adverse events.

\section{Materials and Methods}

This double-blinded, randomized controlled trial was approved by the Research Ethics Board at Hanyang university Guri Hospital (20110021167).

\section{Inclusion and exclusion criteria}

Patients $18-85$ years old who suffered from primary head- ache in the occipital area over three months, including tension-type headache, migraine, new daily persistent headache, and cluster headache were included. Exclusion criteria were 1) patients who had baseline pain of less than $30 \mathrm{~mm}(0-100 \mathrm{~mm}$ Visual analogue scale [VAS]) pain intensity, 2) patients with infection in the area of the injection site, 3 ) patients who had used acute pain medications within 24 hours prior to the study visit, 4) patients with evidence of serious cardiovascular diseases or neurological disorders, 4) patients with known hypersensitivity to the study drugs, 5) pregnant or breast feeding women, and 6) patients who refused to sign a written informed consent form after being informed about the purpose of the study, procedures involved, and potential risks and benefits of the study.

After a written informed consent was obtained, 54 patients with chronic headache in the occipital area were enrolled in this study. We randomized the enrolled patients using the closed-envelope technique into two groups: the bupivacaine (BUP) and the botulinum toxin (BTX) groups. The allocation sequence was generated using a random table number. The BUP group ( $\mathrm{n}$ $=27$ ) was defined as patients receiving the ultrasound-guided GON block with levobupivacaine and dexamethasone and the BTX group $(\mathrm{n}=27)$ as patients receiving the ultrasound-guided GON block with the botulinum toxin type A (Fig. 1).

\section{Methods}

GON blockades were performed with patients in the prone position with mild neck flexion as previously described [7] using a linear-array high frequency $(6-13 \mathrm{MHz})$ ultrasound probe (Sonosite, USA). Some parameters were measured before needle insertion. After confirming the spinous process of $\mathrm{C} 2$, the probe was placed parallel to the laminae of $\mathrm{C} 2$ and slightly rotated

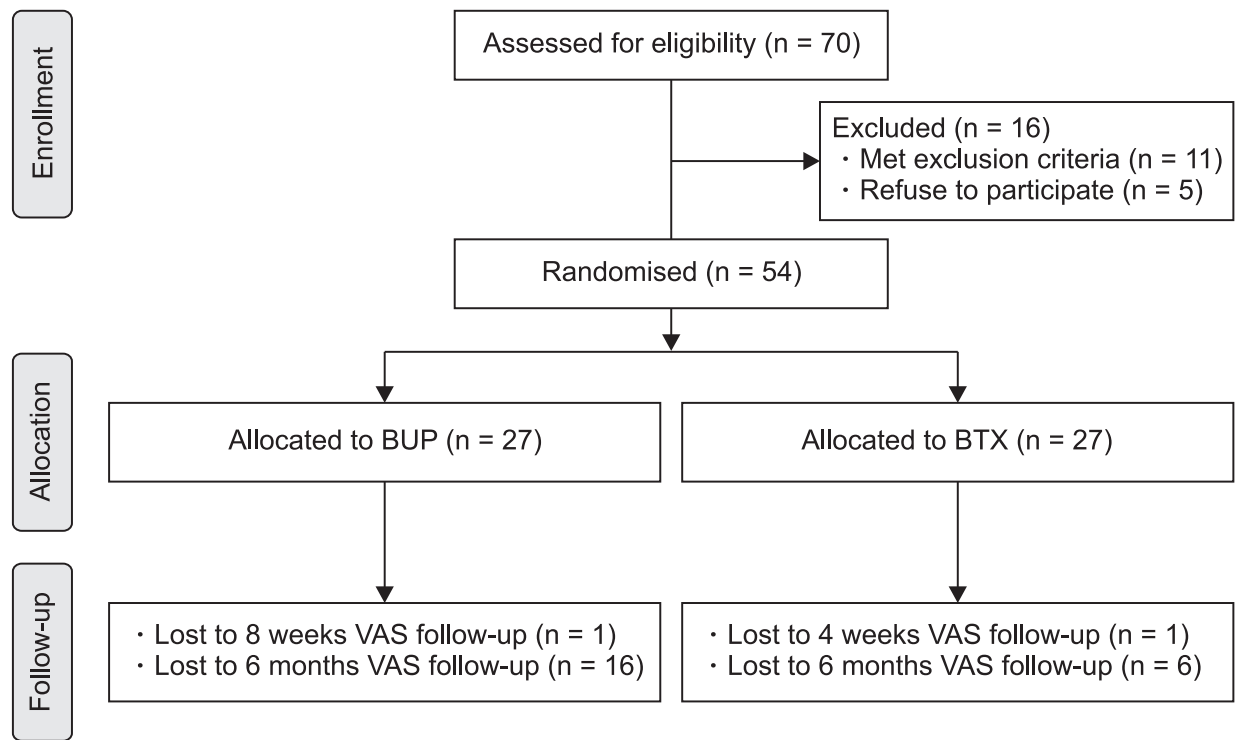

Fig. 1. CONSORT-flow diagram of participants in the study. BUP: bupivacaine, BTX: botulinum toxin, VAS: visual analogue scale. 
along the long axis of the obliquus capitis inferior (OCI) muscle (Fig. 2). The relationship between GON and OCI is reliable and consistent. Therefore, the OCI muscle was used as the primary landmark for searching for GON [8]. After calculating the distance from GON to midline, the distance from the skin surface to GON, and the size of GON, a 23-gauge, $50 \mathrm{~mm}$ block needle was inserted until the tip reached the GON. Patients with headache on both sides were injected on both sides during the same day with the same drug. The anatomical parameters were measured on both sides, but VAS score and pain satisfaction were assessed only for the side with more severe pain.

A total of $1 \mathrm{ml} 0.1 \%$ chirocaine (Levobupvacaine, Abott, USA) and $1 \mathrm{mg}$ dexamethasone (Yuhan, Korea) was prepared for the BUP group [9]. One $\mathrm{ml}$ of 50 units botulinum toxin type A (BoNT-A) (Allergan Inc., USA) was prepared for the BTX group. The same amount of drug for each group was contained in $3 \mathrm{ml}$ syringes and injected by a practitioner blinded to the drugs in the syringes. For both groups, we evaluated the success of the block 15 minutes after injection of the medication. We checked for sensory or motor changes, such as numbness or paralysis of the dermatome. A successful block was defined as the absence of light-touch sensation in the dermatome of GON [8]. The side effects of the injection were determined by clinical symptoms.

Demographic data were collected. The practitioner performing the block, the patient, and the personnel responsible for data collection were blinded to study group allocation. Headache severity was assessed based on the VAS score and patient satisfaction was assessed based on the Likert scale in a blinded manner.

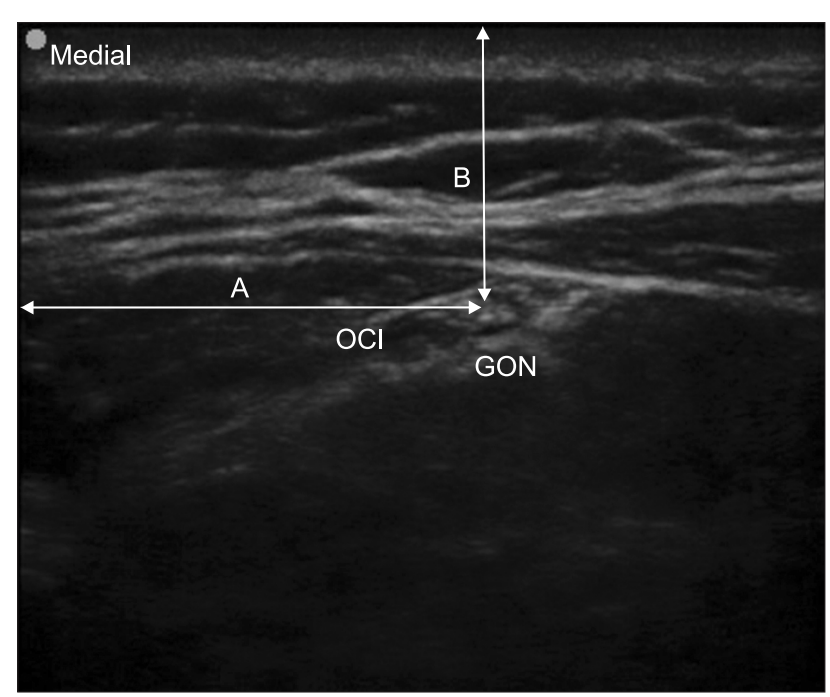

Fig. 2. Ultrasound image of the greater occipital nerve (GON) of the left side away from the midline (spinous process). A is the distance from GON to midline. B is the distance from the skin surface to GON. OCI: obliquus capitis inferior muscle.
Patients were assessed prior to being injected and 1, 4, 8, and 24 weeks after treatment for pain severity. Patients were asked to report the satisfactory score after injection $(1,4,8,24$ weeks) on a 5 -point scale (Likert scale: 1-excellent, 2-good, 3-fair, 4-poor, 5-no effect) when they visited the clinic. Telephone call follow-up was also performed at 24 weeks ( 6 months) postoperatively to assess the satisfactory score if patients did not visit the clinic. If patients felt a headache during the evaluation period, they were administered $500 \mathrm{mg}$ acetaminophen twice per day.

\section{Statistical analyses}

Assuming a power of $80 \%$ and an alpha level of 0.05 , clinical significance $(\varepsilon)$ is generally considered when the difference of VAS score is about $20 \mathrm{~mm}$. The study sample size was set at 27 patients per group considering the expected dropout rate of $20 \%$. Statistical analysis was performed with SAS 9.4 (SAS Institute Inc., USA). Continuous data were tested for normality using the Shapiro-Wilk W statistic. Parametric data were analyzed using Student's $t$-test and non-parametric data were analyzed using the Mann-Whitney $U$ test. Numerical quantitative data were presented by "mean \pm SD" and tested with an independent $t$-test, and categorical data were presented by "frequency (\%)" and tested with a chi-square test or a Fisher's exact test for demographic data and anatomical parameters. The differences in VAS score at pretreatment and $1,4,8$, and 24 weeks after injection were analyzed using the unpaired $t$-test. The differences in Likert scale at $1,4,8$, and 24 weeks after injection were analyzed using the unpaired $t$-test. A P value of 0.05 was chosen as the significance level.

\section{Results}

Seventy patients were screened for enrolment in the study, 54 of whom were recruited and randomized to receive either $0.1 \%$ chirocaine together with $1 \mathrm{mg}$ dexamethasone or a BoNT-A injection (Fig. 1).

A total of 25 patients presented with tension-type headache, 12 with migraine, 9 with cluster headache, and 8 with new daily persistent headache. Eleven tension-type headache patients, 7 migraine patients, 5 cluster headache patients, and 4 patients with new daily persistent headache were included in the BUP group.

Fifteen cases were measured on the right side, 9 cases on the left side, and 3 cases on both sides in the BTX group. In the BUP group, 17 cases were measured on the right side, 9 cases on the left side, and 1 case on both sides. There were no significant differences in patient demographics between the two groups (Table 1).

Each anatomical parameter such as distance from the GON 
to midline, the distance from the skin surface to the GON, and the size of the GON was collected in both groups (Table 2).

The distance from GON to midline (spinous process) in the BTX group was $21.2 \pm 4.9 \mathrm{~mm}$ on the right side and $16.5 \pm 3.9$ $\mathrm{mm}$ on the left side. The distance from GON to midline in the BUP group was $15.0 \pm 3.6 \mathrm{~mm}$ on the right side and $19.6 \pm 4.0$ $\mathrm{mm}$ on the left side. The depth from the skin was $13.4 \pm 1.4$ $\mathrm{mm}$ on the right side and $13.5 \pm 1.5 \mathrm{~mm}$ on the left side in the BTX group, and $12.3 \pm 1.7 \mathrm{~mm}$ on the right side and $13.3 \pm 1.7$ $\mathrm{mm}$ on the left side in the BUP group. GON size was $3.1 \mathrm{~mm}$ on both sides in both groups (Table 2).

There were no statistical differences in the VAS scores before injection and at one week after treatment between the BTX group $(66.8 \pm 3.1$ and $24.9 \pm 3.9)$ and the BUP group $(63.0 \pm 2.8$ and $27.5 \pm 4.5)$. VAS scores at 4,8 , and 24 weeks after treatment were significantly lower in the BTX group $(13.9 \pm 3.3,9.3 \pm 2.6$ and $12.3 \pm 3.8)$ compared to the BUP group $(27.2 \pm 4.1,31.0 \pm$ 4.2 and $34.8 \pm 5.8)($ all $\mathrm{P}<0.05)$ (Fig. 3).

There was no statistical difference in the Likert scale at one week after treatment between groups $(2.1 \pm 0.2$ vs. $2.4 \pm 0.2)$. Likert scales at 4,8 , and 24 weeks after treatment were significantly lower in the BTX group $(1.6 \pm 0.2,1.4 \pm 0.1$ and $1.5 \pm 0.2$,

Table 1. Demographic Data of the Two Groups

\begin{tabular}{lccc}
\hline \multicolumn{1}{c}{ Variable } & BTX $(\mathrm{n}=27)$ & BUP $(\mathrm{n}=27)$ & P value \\
\hline Age $(\mathrm{yr})$ & $52.2 \pm 11.2$ & $55.2 \pm 10.5$ & 0.320 \\
Sex $(\mathrm{M} / \mathrm{F})$ & $7 / 20$ & $8 / 19$ & 0.761 \\
Height $(\mathrm{cm})$ & $160.2 \pm 9.1$ & $158.3 \pm 7.3$ & 0.394 \\
Weight $(\mathrm{kg})$ & $62.6 \pm 11.2$ & $59.9 \pm 8.5$ & 0.335 \\
BMI $\left(\mathrm{kg} / \mathrm{m}^{2}\right)$ & $24.3 \pm 3.2$ & $23.9 \pm 2.3$ & 0.577 \\
Nerve Block site & & & \\
Right & $15(55.56)$ & $17(62.97)$ & 0.757 \\
Left & $9(33.33)$ & $9(33.33)$ & \\
Both & $3(11.11)$ & $1(3.7)$ & \\
\hline
\end{tabular}

Numerical quantitative data tested with an independent $t$-test are presented as "mean \pm SD" and categorical data tested with a chi-square test or Fisher's exact test are presented as "frequency (\%)." BTX: botulinum toxin, BUP: bupivacaine, BMI: body mass index.

Table 2. Anatomic Parameters of the BUP and BTX Groups

\begin{tabular}{lrrrrrr}
\hline \multirow{2}{*}{ Variable } & \multicolumn{2}{c}{ BTX $(\mathrm{n}=27)$} & & \multicolumn{2}{c}{ BUP $(\mathrm{n}=27)$} \\
\cline { 2 - 3 } \cline { 5 - 6 } & \multicolumn{2}{c}{ Right } & Left & & Right & Left \\
\hline NSD $(\mathrm{mm})$ & $21.2 \pm 4.89$ & $16.54 \pm 3.91$ & & $15.04 \pm 3.64$ & $19.63 \pm 3.97$ \\
NPD $(\mathrm{mm})$ & $13.38 \pm 1.37$ & $13.54 \pm 1.53$ & & $12.25 \pm 1.68$ & $13.25 \pm 1.74$ \\
GON size $\left(\mathrm{mm}^{2}\right)$ & $3.05 \pm 0.25$ & $3.07 \pm 0.42$ & & $3.09 \pm 0.35$ & $3.05 \pm 0.30$
\end{tabular}

Numerical quantitative data tested with an independent $t$-test are presented as "mean \pm SD." BTX: botulinum toxin, BUP: bupivacaine, NSD: distance from GON to midline (spinous process), NPD: distance from the skin surface to GON, GON: greater occipital nerve. respectively) compared to the BUP group $(2.4 \pm 0.2,2.8 \pm 0.2$ and $3.1 \pm 0.3$, respectively) (all $\mathrm{P}<0.05$ ) (Fig. 4).

Adverse effects such as direct paralysis, flu-like symptoms, dizziness, vaso-vagal syncopal attack, allergic reactions, exaggerated headaches, and major complications were not reported.

\section{Discussion}

Headache disorders are among the most common disor-

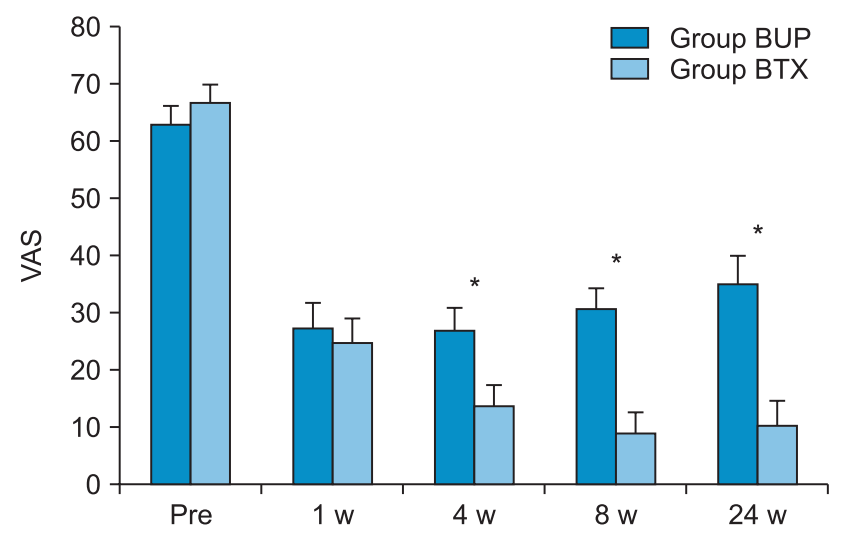

Fig. 3. Comparison of the visual analogue scale (VAS) scores between the two groups for each time course. Group BUP $(n=27)$ defined as patients with ultrasound-guided greater occipital nerve (GON) block with bupivacaine and group BTX $(\mathrm{n}=27)$ as patients with ultrasoundguided GON block with botox A. One patient in the BUP group dropped out, because he/she could not be contacted to obtain the VAS score at 8 weeks. ${ }^{*} \mathrm{P}<0.05$ compared with $4 \mathrm{~W}, 8 \mathrm{~W}, 24 \mathrm{~W}$ between for both groups. Pre: before greater occipital nerve block, $1 \mathrm{~W}: 1$ week after block, 4 W: 4 weeks after block, 8 W: 8 weeks after block, 24 W: 24 weeks after block.

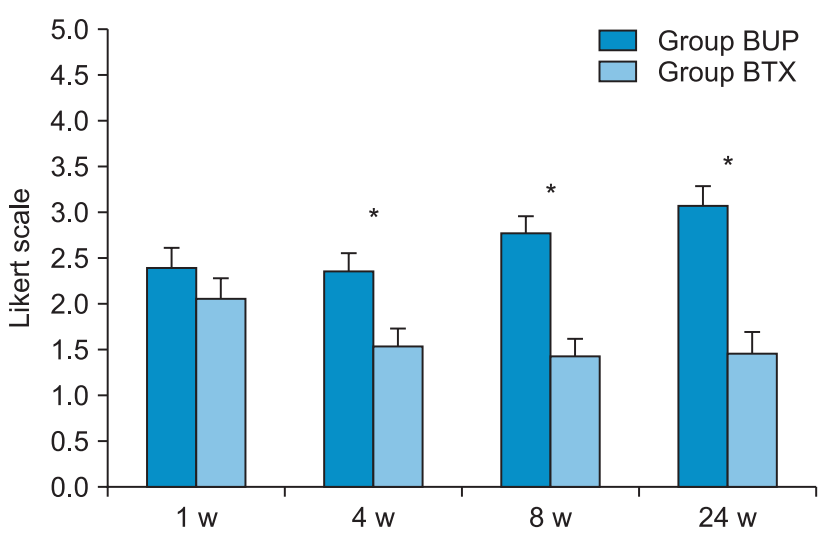

Fig. 4. Comparison of Likert Scale between the two groups for each time course. Group BUP ( $n=27)$ defined as patients with ultrasoundguided greater occipital nerve (GON) block with bupivacaine and group BTX $(n=27)$ as patients with ultrasound-guided GON block with botox A. ${ }^{*} \mathrm{P}<0.05$ comparison between $1 \mathrm{~W}$ and $4 \mathrm{~W}, 8 \mathrm{~W}$, or $24 \mathrm{~W}$ for both groups. $1 \mathrm{~W}$ : 1 week after block, $4 \mathrm{~W}: 4$ weeks after block, $8 \mathrm{~W}: 8$ weeks after block, $24 \mathrm{~W}$ : 24 weeks after block. Likert scale: 1-excellent, 2-good, 3-fair, 4-poor, 5-no effect. 
ders of the nervous system. It has been estimated that $46 \%$ of the adult population have headache at least once per year [10]. Because of their high prevalence, socioeconomic and personal effects are very significant. Headache disorders can be categorized into cevicogenic headache, occipital neuralgia, tension headache, migraine, and cluster headache according to the $3 \mathrm{rd}$ International Classification of Headache Disorders [1]. Recently it has been newly categorized according to the 3rd International Classification of Headache Disorders [1].

Blocking the sensory nerve is a useful method for immediate reduction of pain. Several studies have suggested that blocking GON is effective for various kinds of headaches, such as cervicogenic headache $[3,4]$, occipital neuralgia [11], tension headache [4], primary headache [12], cluster headache [13], and even migraine [5]. GON block is effective in the treatment of headaches due to the convergence of the sensory input to the trigeminal nucleus caudalis neurons from both trigeminal and cervical nerve fibers [5,14], and its role in antagonizing a putative "windup-like effect" that can explain headache improvement [3].

Many practitioners still perform GON injections using a conventional approach with or without ultrasound, depending entirely on conventional anatomic landmarks to inject local anesthetic and corticosteroid around the nerve at the level of the superior nuchal line $[9,15]$. Practitioners are increasingly using ultrasound for peripheral nerve block because ultrasound helps to determine the exact location of the nerve, minimizing complications and increasing the chances of success with small quantities of the drug.

GON originates from the medial branch of the posterior division of the second cervical spinal nerve with variable contribution from the $\mathrm{C} 3$ dorsal ramus, and traverses the posterior scalp and neck. Ducic et al. [16] reported that GON proceeds between OCI and the semispinalis capitis muscle and then pierces medially to the semispinalis capitis muscle. It courses obliquely, in a superolateral fashion and is considerably more lateral at the level of the occipital prominence $[11,17]$.

Greher et al. [7] described a proximal approach at the level of C2, targeting GON superficial to the OCI muscle. They mentioned that GON blockade at the level of C2 has a higher success rate and is more precise compared with site at the level of the superior nuchal line using ultrasound guidance [7]. The block success rate was $80 \%$ (95\% CI: $58 \%, 93 \%)$ at classic site vs. $100 \%$ (95\% CI: $86 \%, 100 \%)$ at a new proximal site in that study. In our study, proximal blocking at the level of C2 using ultrasound guidance was $100 \%$ successful. In their cadaver study, the authors [7] determined that the distance from GON to the $\mathrm{C} 2$ spinous process (NSD) was $27.6 \mathrm{~mm}$ (18.9-32.6 mm). In our study, NSD was $21.2 \pm 4.9 \mathrm{~mm}$ in the right side and $16.5 \pm 3.9$ $\mathrm{mm}$ in the left side in the BTX group and $15.0 \pm 3.6 \mathrm{~mm}$ in the right side and $19.6 \pm 4.0 \mathrm{~mm}$ in the left side in the BUP group.
The depth from the skin was $17.5 \mathrm{~mm}(9.8-29.0 \mathrm{~mm})$ in the cadaver study [7]. In our study, the depth was $13.4 \pm 1.4 \mathrm{~mm}$ in the right side and $13.5 \pm 1.5 \mathrm{~mm}$ in the left side in the BTX group, and $12.3 \pm 1.7 \mathrm{~mm}$ in the right side and $13.3 \pm 1.7 \mathrm{~mm}$ in the left side in the BUP group. In our study, NSD and depth from the skin were shorter, which could be explained due to the difference in height, weight, and bone mass index of the patients between the two studies.

We used a mixture of $1 \mathrm{ml} 0.1 \%$ chirocaine 0.1 and $1 \mathrm{mg}$ dexamethasone, consistent with a previous study [9]. Such a small amount would be sufficient for GON blockade under ultrasound guidance according to that study. The dose of BoNT-A used for chronic headache or myofascial pain syndrome varies from $5 \mathrm{U}$ to $100 \mathrm{U}[18,19]$. Kapural et al. [20] mentioned that the mean VAS score was significantly reduced from $8 \pm 1.8$ to $2 \pm 2.7$ and the Pain Disability Index was reduced from $51.5 \pm$ 17.6 to $19.5 \pm 21$ using $50 \mathrm{U}$ botulinum toxin in occipital nerve block for the treatment of severe occipital neuralgia and the duration of the pain relief was increased to an average of $16.3 \pm 3.2$ weeks. Therefore we used $1 \mathrm{ml} 0.1 \%$ chirocaine and $1 \mathrm{mg}$ dexamethasone for the BUP group and $1 \mathrm{ml}$ of 50 units BoNT-A for the BTX group $[9,13,20,21]$.

BTX is a neurotoxic protein produced by the bacterium Clostridium botulinum and related species [22]. It prevents the release of the neurotransmitter acetylcholine from axon endings at the neuromuscular junction and thus causes flaccid paralysis. BTX exerts its effect by cleaving key proteins required for nerve activation. First, the toxin binds specifically to nerves which use the neurotransmitter acetylcholine. Once bound to the nerve terminal, neurons take up the toxin into vesicles by receptor-mediated endocytosis [23]. As the vesicles move further into the cell, a portion of the toxin travels across the vesicle membrane into the cytoplasm [22]. Once inside the cytoplasm, the toxin cleaves SNARE proteins, therefore the acetylcholine vesicles cannot bind to the intracellular membranes, preventing the release of the neurotransmitter from the vesicle, thus impairing nerve signaling, leading to paralysis [22].

BTX types A and B are used in medicine to treat various muscle spasms and diseases [20]. BTX is used to treat muscle spasticity, muscle disorders like strabismus [24], hyperhidrosis [25], chronic headache [20], not to mention cosmetic uses [26]. Binder et al. [6] reported that patients who had cosmetic injections around the face did not suffer from chronic headaches. This was initially thought to be an indirect effect of reduced muscle tension, but it is now known that the toxin inhibits release of peripheral nociceptive neurotransmitters, suppressing the central pain processing systems responsible for migraine headache [27]. FDA approved intramuscular BTX injections for prophylactic treatment of chronic migraine headache in 2010 [28]. 
The unusual side effects of GON blockade include transient post-injection dizziness, vaso-vagal syncopal attack, hair loss around the injection site and exaggerated headache [29]. The side effects of BoNT-A are not limited to direct paralysis and can also include flu-like symptoms, headaches, and allergic reactions [30]. Side effects from therapeutic use can be much more diverse depending on the location of the injection and the dose of the injected toxin. In general, side effects can be more serious during therapeutic use than during cosmetic use. These derive from paralysis of critical muscle groups and can include arrhythmia, heart attack, and in some cases seizures, respiratory arrest, and even death [30]. In our study, no adverse effects were observed for used drugs such as BoNT-A or local anesthetic agents.

A major limitation of this study is the high dropout rate at six months VAS. Patients who were not satisfied with the treatment may not have continued visiting the outpatient clinic. Therefore, 6 patients dropped out after 24 weeks in the BTX group, and 16 in the BUP group, and the VAS score was evaluated after 24 weeks only in 11 patients in the BUP group. Therefore, the VAS score at 24 weeks after treatment in the BUP group was relatively low. However, the evaluation of patient satisfaction was relatively accurate because there was no dropout in the face-to-face and phone call evaluations. Therefore, it is possible that patient satisfaction and treatment effectiveness at 24 weeks after treatment is better for the BTX group, compared to the BUP group.

Second, this study could not confirm the treatment efficacy and satisfaction of headache patients with specific causes. In future studies, the causes of each headache should be subdivided, and each treatment effect and satisfaction should be confirmed. Nevertheless, this study evaluated the safety and efficacy of GON block at the second cervical vertebra level under ultrasonography for the treatment of chronic occipital headache and suggested the possibility of using BTX.

In conclusion, ultrasound guided GON block at the proximal site at the C2 level was an effective and relatively safe treatment method and patient satisfaction and treatment effect of BTX were higher than local anesthetics during long-term follow-up.

\section{Acknowledgments}

We thank Donghee Son and Yun Jin Kim in the Biostatistical Consulting and Research Lab, Hanyang University for assistance with statistical analysis.

\section{Funding Statement}

Dr. Jae Hang Shim was supported by the Medical Research Collaborating Center, Hanyang University.

\section{Conflicts of Interest}

No potential conflict of interest relevant to this article was reported.

\section{Author Contributions}

Jae Hyung Ryu (Data curation; Writing-original draft)

Jae Hang Shim (Funding acquisition; Methodology; Writingoriginal draft; Writing-review \& editing)

Jong Hoon Yeom (Visualization)

Woo Jong Shin (Validation)

Sang Yun Cho (Supervision)

Woo Jae Jeon (Visualization)

\section{ORCID}

Jae Hyung Ryu, https://orcid.org/0000-0001-9334-8791 Jae Hang Shim, https://orcid.org/0000-0002-3533-6407 Jong Hoon Yeom, https://orcid.org/0000-0003-3159-2072 Woo Jong Shin, https://orcid.org/0000-0002-3786-2267 Sang Yun Cho, https://orcid.org/0000-0002-6593-1960 Woo Jae Jeon, https://orcid.org/0000-0002-9662-4197

\section{References}

1. Headache Classification Committee of the International Headache Society (IHS). The International Classification of Headache Disorders, 3rd edition (beta version). Cephalalgia 2013; 33: 629-808.

2. Bogduk N. The clinical anatomy of the cervical dorsal rami. Spine (Phila Pa 1976) 1982; 7: 319-30.

3. Vincent MB, Luna RA, Scandiuzzi D, Novis SA. Greater occipital nerve blockade in cervicogenic headache. Arq Neuropsiquiatr 1998; 56: $720-5$.

4. Bovim G, Sand T. Cervicogenic headache, migraine without aura and tension-type headache. Diagnostic blockade of greater occipital and supra-orbital nerves. Pain 1992; 51: 43-8.

5. Young W, Cook B, Malik S, Shaw J, Oshinsky M. The first 5 minutes after greater occipital nerve block. Headache 2008; 48: 1126-8.

6. Binder WJ, Brin MF, Blitzer A, Schoenrock LD, Pogoda JM. Botulinum toxin type A (BOTOX) for treatment of migraine headaches: an open-label study. Otolaryngol Head Neck Surg 2000; 123: 669-76. 
7. Greher M, Moriggl B, Curatolo M, Kirchmair L, Eichenberger U. Sonographic visualization and ultrasound-guided blockade of the greater occipital nerve: a comparison of two selective techniques confirmed by anatomical dissection. Br J Anaesth 2010; 104: 637-42.

8. Pingree MJ, Sole JS, O囚 Brien TG, Eldrige JS, Moeschler SM. Clinical efficacy of an ultrasound-guided greater occipital nerve block at the level of C2. Reg Anesth Pain Med 2017; 42: 99-104.

9. Shim JH, Ko SY, Bang MR, Jeon WJ, Cho SY, Yeom JH, et al. Ultrasound-guided greater occipital nerve block for patients with occipital headache and short term follow up. Korean J Anesthesiol 2011; 61: 50-4.

10. Stovner Lj, Hagen K, Jensen R, Katsarava Z, Lipton R, Scher A, et al. The global burden of headache: a documentation of headache prevalence and disability worldwide. Cephalalgia 2007; 27: 193-210.

11. Natsis K, Baraliakos X, Appell HJ, Tsikaras P, Gigis I, Koebke J. The course of the greater occipital nerve in the suboccipital region: a proposal for setting landmarks for local anesthesia in patients with occipital neuralgia. Clin Anat 2006; 19: 332-6.

12. Lim HB, Hunt K. Anesthetic management for surgical placement of greater occipital nerve stimulators in the treatment of primary headache disorders. J Neurosurg Anesthesiol 2007; 19: 120-4.

13. Ambrosini A, Vandenheede M, Rossi P, Aloj F, Sauli E, Pierelli F, et al. Suboccipital injection with a mixture of rapid- and long-acting steroids in cluster headache: a double-blind placebo-controlled study. Pain 2005; 118: 92-6.

14. Bartsch T, Goadsby PJ. Stimulation of the greater occipital nerve induces increased central excitability of dural afferent input. Brain 2002; 125: 1496-509.

15. Lauretti GR, Corrêa SW, Mattos AL. Efficacy of the greater occipital nerve block for cervicogenic headache: comparing classical and subcompartmental techniques. Pain Pract 2015; 15: 654-61.

16. Ducic I, Moriarty M, Al-Attar A. Anatomical variations of the occipital nerves: implications for the treatment of chronic headaches. Plast Reconstr Surg 2009; 123: 859-63.

17. Cesmebasi A, Muhleman MA, Hulsberg P, Gielecki J, Matusz P, Tubbs RS, et al. Occipital neuralgia: anatomic considerations. Clin Anat 2015; 28: 101-8.

18. Graboski CL, Gray DS, Burnham RS. Botulinum toxin A versus bupivacaine trigger point injections for the treatment of myofascial pain syndrome: a randomised double blind crossover study. Pain 2005; 118: 170-5.

19. Ho KY, Tan KH. Botulinum toxin A for myofascial trigger point injection: a qualitative systematic review. Eur J Pain 2007; $11: 519-27$.

20. Kapural L, Stillman M, Kapural M, McIntyre P, Guirgius M, Mekhail N. Botulinum toxin occipital nerve block for the treatment of severe occipital neuralgia: a case series. Pain Pract 2007; 7: 337-40.

21. Ashkenazi A, Matro R, Shaw JW, Abbas MA, Silberstein SD. Greater occipital nerve block using local anaesthetics alone or with triamcinolone for transformed migraine: a randomised comparative study. J Neurol Neurosurg Psychiatry 2008; 79: 415-7.

22. Montecucco C, MolgóJ. Botulinal neurotoxins: revival of an old killer. Curr Opin Pharmacol 2005; 5: 274-9.

23. Dressler D, Saberi FA, Barbosa ER. Botulinum toxin: mechanisms of action. Arq Neuropsiquiatr 2005; 63: 180-5.

24. Flanders M, Tischler A, Wise J, Williams F, Beneish R, Auger N. Injection of type A botulinum toxin into extraocular muscles for correction of strabismus. Can J Ophthalmol 1987; 22: 212-7.

25. Bushara KO, Park DM, Jones JC, Schutta HS. Botulinum toxin--a possible new treatment for axillary hyperhidrosis. Clin Exp Dermatol 1996; 21: 276-8.

26. Clark RP, Berris CE. Botulinum toxin: a treatment for facial asymmetry caused by facial nerve paralysis. Plast Reconstr Surg 1989; 84: 353-5.

27. Ramachandran R, Yaksh TL. Therapeutic use of botulinum toxin in migraine: mechanisms of action. Br J Pharmacol 2014; 171: 4177-92.

28. Lew MF. Review of the FDA-approved uses of botulinum toxins, including data suggesting efficacy in pain reduction. Clin J Pain 2002; $18(6$ Suppl): S142-6.

29. Afridi SK, Shields KG, Bhola R, Goadsby PJ. Greater occipital nerve injection in primary headache syndromes--prolonged effects from a single injection. Pain 2006; 122: 126-9.

30. CotéTR, Mohan AK, Polder JA, Walton MK, Braun MM. Botulinum toxin type A injections: adverse events reported to the US Food and Drug Administration in therapeutic and cosmetic cases. J Am Acad Dermatol 2005; 53: 407-15. 